\title{
Obstáculos para una investigación social orientada al desarrollo
}

José Padrón Guillén

Conferencia en el I Seminario Nacional de Ciencias Sociales

Universidad de Carabobo, Valencia, Venezuela

En el área de las Ciencias Sociales lucho contra el hábito de falsificar las cosas.

(Karl Popper)

$\mathbf{E}$ objetivo de esta intervención es plantear algunos de los problemas u obstáculos más graves que enfrenta la investigación en Ciencias Sociales en general.

Al hablar de problemas y obstáculos se alude a factores que en mayor o menor medida blo-quean el desarrollo de soluciones científicas y tecnológicas que satisfagan las necesidades de desarrollo social. Y, al hablar de desarrollo social, hago referencia a una visión colectivista de la sociedad y de las relaciones económicas, aquella visión no piramidal, no competitiva, que aboga por la inclusión de las grandes masas desposeídas en la dinámica productiva y que se opone a esa otra visión individualista, excluyente, según la cual el esfuerzo individual y el retroceso de los demás es el secreto para ascender en la pirámide social donde, en el vértice, están los pocos que tienen mucho y, en la base, están los muchos que tienen poco (o nada).

Si lograran minimizarse esos factores, la Investigación en Ciencias Sociales constituiría una herramienta poderosa para avanzar hacia una sociedad independiente, autosustentada, justa y, en fin, desarrollada. Creo firmemente en que no hay desarrollo si sólo lo disfrutan unos pocos y que la inde-pendencia y la soberanía de las sociedades dependen de sus mecanismos de inclusión/exclusión. La investigación científica y social debe tomar partido frente a ambos mecanismos. En esta intervención se asume como "obstáculo" todo aquello que se pliega a los factores individualistas y competitivistas de exclusión social y se sugieren fórmulas de superación que conduzcan a una Investigación Social orientada al desarrollo amplio, incluyente, en los términos ya reseñados.

\section{CONCEPTUACIONES PREVIAS}

Hay algunas precisiones importantes que deben hacerse antes de abordar esos factores inhibidores. En primer lugar, cuando hablamos de investigación nos estamos refiriendo a la Investigación científica, entendida como aquella clase de procesos de producción de conocimiento científico y tecnológico. No estamos entonces considerando dentro del término investigación aquellos productos como las obras literarias, por ejemplo, las reflexiones libres, las especulaciones filosóficas sin base argumental ni empírica, las revelaciones intimistas, los textos esotéricos, etc. En general, partimos aquí de la idea de que el conocimiento es representación cognitiva de la realidad $y$, aunque todo conocimiento tiene vinculaciones estrechas e inevitables con las esferas 
afectiva y sensorial, no es válido confundirlo con éstas. No podemos tratar el conocimiento como si fuera idéntico a los sentimientos y a las percepciones. Por eso, al hablar de conocimientos, hacemos referencia a aquellas redes representacionales que se forman en la esfera cognitiva de las personas y no a cosas como las emociones y las impresiones sensoriales.

Por otra parte, cuando decimos que un conocimiento es científico, queremos decir que tiene altos valores de socialización y de sistematización, además de una base teórica explícita. Un conocimiento es altamente socializado en la medida en que más escape de los límites de la conciencia unipersonal, individual, y se proyecte hacia el dominio de los intereses de grandes grupos sociales. Se opone así al conocimiento íntimo, subjetivo, personalizado o individualizado. Un buen ejemplo del conocimiento íntimo nos lo ofrece san Agustín en sus "Confesiones", cuando dice que él sabe lo que es el tiempo si nadie se lo pregunta, pero que ya deja de saberlo cuando alguien se lo pregunta. Ese tipo de conocimiento que tiene san Agustín sobre el tiempo carece de valores de socialización. En cambio, los conocimientos sobre cosas como el cáncer, el sistema solar, etc., tienen altos valores de socialización, sin que por ello sean necesariamente científicos. Para que esto ocurra se requiere que al mismo tiempo tengan altos niveles de sistematización y que estén asociados a una base teórica explícita. Un conocimiento es altamente sistematizado cuando los procesos que lo generan y lo sustentan son estandarizados, canónicos, repetibles, comunicables, de modo que cualquiera, dentro de las circunstancias adecuadas, pueda replicarlo cuando lo desee. En esto la Ciencia se diferencia del Arte, entre otras cosas. Los procesos que generan una obra de arte, especialmente los que definen su creatividad, son imposibles de estandarizar, de organizar en una serie de pasos e instrucciones, por más que, socio-históricamente hablando, la producción artística haya sido "institucionalizada" y sometida a cánones (ver Araujo-Valero, 2009). Lo mismo ocurre con la Magia: Ios caminos de la mente del mago son impenetrables, y nadie sabe cómo funcionan. Un caso típico de conocimiento sistematizado es el de la mayoría de las recetas de cocina, ya que basta con tener los ingredientes e instrumentos y con seguir las instrucciones para obtener el plato deseado.

Alguien podría suponer que el caso de las recetas de cocina es de tipo científico, ya que el conocimiento culinario tiene altos niveles de socialización y de sistematización, pero eso no basta. Se requiere además de un componente teórico que esté indisolublemente asociado, sin el cual resulte imposible el manejo del conocimiento en cuestión. Es evidente que el conocimiento culinario tiene sus bases teóricas en la física, la química y la biología, pero éstas no son indispensables para producir y consumir ese conocimiento. Con esto último excluimos del concepto de Investigación Científica también aquellas elaboraciones que son sólo de tipo técnico y de réplica metodológica, como es el caso de la producción de software basada en un protocolo preexistente, los diseños curriculares e instruccionales, las biografías y reseñas de personajes y los registros históricos, entre otras cosas. Es diferente el caso de las investigaciones tecnológicas, cuando el producto obtenido tiene altos niveles de socialización y sistematización y, además, se deriva de alguna teoría plausible, como, por ejemplo, la producción de software pionero, las tecnologías de diseño curricular, las biografías como correlatos empíricos de algunas teorías, etc.

Otra precisión importante antes de entrar en el tema es que no existe una sola manera de investigar ni podemos, en principio y en términos absolutos, creer que un cierto modo de investigar es mejor que los demás. Esto se opone a lo que podríamos llamar proselitismo investigativo, aquella nefasta tendencia a convencer a todos de que un cierto patrón de investigación es el mejor de todos, mientras que todos los demás resultan rechazables. Es así como en muchas de 
nuestras universidades a menudo se impone desde arriba un único patrón de trabajo y se pretende obligar a todos a seguirlo:

Cuando un estudiante llega a la universidad, no sabe qué criterios aplicar y, así, adopta los que encuentre. Y como los estándares intelectuales en la mayoría de los departamentos de Filosofía (y especialmente de Sociología) permiten la pomposidad y el presunto conocimiento (toda esta gente parece saber muchísimo), aún las mejores inteligencias quedan desviadas. (Popper, 1992: 86. Trad. propia).

Esta tendencia constituye uno de los más fuertes obstáculos a las investigaciones orientadas al desarrollo. Los patrones de trabajo investigativo dependen estrictamente de la configuración cognitiva del investigador y de su sistema de convicciones epistemológicas, todo lo cual difiere de unos individuos a otros y, por tanto, es absurdo pretender imponer a unos individuos el sistema de trabajo que es ajeno a su propia configuración cognitiva y a sus propias visiones epistemológicas. Para ello hay que partir de las nociones de estilos de pensamiento y de enfoques epistemológicos.

Estos dos conceptos, que han sido desarrollados en varios trabajos anteriores, ${ }^{1}$ pueden sintetizarse en la siguiente cadena de ideas: i) el individuo, desde su nacimiento, se enfrenta a la tarea de resolver problemas: ii) en su diario ejercicio de resolución de problemas el individuo va consolidando un cierto patrón operativo compuesto por aquellas estrategias que le resultan más exitosas; iii) ese patrón estratégico define sus preferencias operativas y se convierte en una configuración cognitiva estable y diferenciada, llamada estilo de pensamiento, el cual se activa sistemáticamente frente a situaciones de planteamiento y resolución de problemas; iv) los individuos se asemejan o diferencian entre sí por la predominancia de un determinado estilo de pensamiento; v) cuando los Estilos de Pensamiento se aplican a la resolución de problemas en el mundo de la Ciencia se convierten en enfoques epistemológicos; vi) Un enfoque epistemológico es un sistema pre-teórico y universal de convicciones en torno a la naturaleza del conocimiento y a sus vías válidas de producción, el cual domina y encuadra todos los trabajos de un investigador; vii) cuando varios investigadores líderes se unen en programas de trabajo, tienden a controlar y a dominar la producción investigativa de su comunidad científica por la vía de su propio Enfoque Epistemológico, generando un "Paradigma" (en el sentido de Kuhn, 1962).

Una vez entendidos estos dos conceptos, podríamos considerar diferentes clasificaciones de enfoques epistemológicos, los cuales generan distintos patrones metodológicos de investigación. Existen varias de estas clasificaciones. En la línea de investigación a la que pertenezco² utilizamos una que tiene una versión simplificada y una versión extendida. Me referiré aquí a la versión simplificada, la cual considera tres tipos básicos: el enfoque empirista-Inductivista $(E I)$, que trabaja con observaciones, mediciones y leyes; el enfoque racionalista-deductivista $(R D)$, que trabaja con deducciones, cadenas de razonamiento y modelos lógicomatemáticos; y el enfoque vivencialista-interpretativista $(V I)$, que trabaja con introspecciones, empatías e interpretaciones socio-simbólicas.

El primero de ellos, el El, se enfoca en la convicción de que en la frecuencia de hechos repetidos se revelan patrones y regularidades que pueden ser 'descubiertos' y traducidos a 'leyes'. Para el El, la investigación científica ha de orientarse sólo a hechos y objetos 'observables', que puedan ser captados por los sentidos. El El generó el paradigma newtonia-

\footnotetext{
1 Sobre estilos de pensamiento, ver Padrón (2008). Sobre enfoques epistemológicos, ver Padrón, Hernández y Di Gravia, A. (2005). Para ambas cosas, ver Rivero (2000).

2 LINEA-i, Línea de Investigaciones en Enseñanza / Aprendizaje de la Investigación, en www.lineai.org.
} 
no en física y, más recientemente, los paradigmas positivista (Augusto Comte) y neopositivista (Círculo de Viena).

El segundo de ellos, el $R D$, se enfoca en la convicción de que las infinitas variedades del mundo pueden sintetizarse en estructuras universales abstractas (matemáticas, en sentido muy amplio) que pueden ser 'inventadas' y 'diseñadas' por el investigador en forma de modelos, tanto en lenguaje lógico, como en lenguaje matemático, como en lenguaje gráfico-diagramático o en cualquier lenguaje artificial. Para el $R D$ la investigación científica no sólo debe orientarse a los hechos y objetos 'observables', sino sobre todo a los hechos y objetos 'pensables' o 'calculables', aquellos que no pueden captarse con los sentido, sino con el razonamiento. El $R D$ generó el paradigma einsteniano en física teórica, el paradigma chomskyano en lingüística teórica, el paradigma mendeleievano en química, etc.

El tercero de ellos, el $V I$, se enfoca en la convicción de que los hechos humanos son totalmente diferentes a los hechos materiales y deben resolverse de un modo distinto $y$, por tanto, la única solución posible es interactuar con esos hechos poniéndose en medio de ellos o en el lugar de quienes los viven y tratando de interpretar qué significado de fondo tienen, siempre viendo las cosas desde el propio contenido de conciencia. Es como si el mundo debiera entenderse desde la propia representación en la conciencia individual y no desde su existencia objetiva en el mundo físico. Generan sus resultados de investigación en términos de interpretaciones personales, en lenguaje ordinario impregnado de rasgos académicos y filosóficos. Para el VI, la investigación científica del terreno de las Ciencias Sociales debe considerar los hechos y objetos 'vivibles', 'experienciables', más allá de los objetos 'observables' (EI) y 'pensables' (RD).

Si la base de la noción de Enfoque Epistemológico está en la idea de Estilo de Pensamiento y si, a su vez, esta segun- da idea tiene un fuerte apoyo teórico y empírico (ver evidencias y referencias en Padrón, 2008), entonces debemos considerar los Enfoques Epistemológicos como la principal fuente de variaciones en el modo en que trabajan los investigadores y, más allá de eso, debemos considerar tales variaciones como legítimos intentos de producción científica, sin descalificar a ninguno de ellos y sin pretender imponer alguno en particular. Esta noción se convierte en el principal argumento contra los proselitismos epistemológicos y metodológicos y contra esa absurda tendencia a la persuasión académica (que es, al fin de cuentas, una forma particular de clientelaje y dominación).

Una vez hechas estas precisiones, podemos pasar ahora a considerar algunos obstáculos para el crecimiento de la investigación científica del área social orientada al desarrollo masivo. Para efectos de discriminación y explicación, las dividiremos según el área de responsabilidad en la que se enmarcan tales obstáculos: los provenientes de la esfera institucional-organizacional, los provenientes de la esfera epistemológico-metodológica y los que se adscriben a un ámbito axiológico o de valores. En cada esfera citaré algunos ejemplos, pero no significa que esos ejemplos agoten toda la descripción ni que sean los más representativos: el estado de cosas es mucho más vasto y podrían escribirse varios tomos a la hora de hacer una descripción completa.

\section{LOS OBSTÁCULOS ORGANIZACIONALES}

Hay muchas deficiencias en la producción de investigaciones que suelen ser atribuidas a los individuos, cuando en realidad derivan de las mismas instituciones y de ciertas configuraciones organizacionales. Uno de los ejemplos más claros es el llamado "Síndrome TMT" (todo menos tesis: Valarino, 1991), que luego derivó en muchos otros "síndromes" (TMTA: todo menos trabajo de ascenso, TMl: todo menos investigación, TME: todo, menos extensión, etc.), y que hasta 
llegó a considerarse un problema médico, no metafórico, con etiología, terapia y contraindicaciones (por ejemplo, Salinas, 1998). Aparte del contrasentido de Ilamarlo "síndrome", ya que no se trata de ninguna enfermedad, no suele ser el sujeto el responsable de no hacer una tesis, sino las complicadas trabas institucionales, tanto burocráticas como curriculares. En todo caso, si habláramos de "síndrome TMT" en sentido metafórico, es a la institución a quien debería aplicársele y no al individuo. Examinando de cerca los factores que intervienen en la deserción de la tesis, vemos que casi siempre se debe a la total desvinculación entre la carga académica y la tesis, lo que se refleja en el hecho de dejar para el final la producción de la misma, cuando ya el tesista se halla en la más profunda soledad académica: sin compañeros, sin profesores, sin ambiente de trabajo, sin recursos bibliográficos y acosado además por las incoherencias e intransigencias de cierto tipo de evaluadores (me refiero a determinados comités de trabajo de grado, profesores de metodología, asesores metodológicos y a un particular conjunto de burócratas que actúan más como Torquemada en la Inquisición que como colaboradores). Veamos, a modo de ilustración, algunos de estos factores en esta área organizacional.

\subsection{La universidad profesionalizante}

Probablemente el obstáculo madre de todos los demás es la función profesionalizante que tienen todavía nuestras instituciones de educación superior y de postgrado. Esa función se implantó en Latinoamérica en aquella época del cambio de países campesinos a países urbanos, cuando la industria y la empresa privada dejaron de necesitar fuerza bruta o trabajo sanguíneo y comenzaron a requerir de personal calificado. Proliferaron entonces las instituciones de educación superior con la función de suplir al sector empresarial de mano de obra barata. Si bien al principio los egresados de educación superior tenían una remuneración aceptable y hasta ventajosa, de lo cual surgieron nuestras clases medias latinoamericanas, con el paso del tiempo la oferta universitaria superó la demanda empresarial y las remuneraciones Ilegaron a niveles inaceptables, hasta el punto de que actualmente se tiene mucho mayores ingresos como taxista, por ejemplo, que como profesional de tercer nivel. Con el objeto de compensar el desequilibrio oferta/demanda, surgieron los postgrados, primero las especializaciones y maestrías y luego los doctorados, los cuales han sido una verdadera explosión especialmente en las universidades privadas, que, según su conocida actitud, vieron ahí una oportunidad de negocio. Últimamente están surgiendo los postdoctorados, de los cuales no sabemos todavía si responden a genuinas necesidades sociales o a simples vanidades académicas, personales y grupales (más asociadas a la burocracia que a la Academia, según veremos más adelante).

Pero, aun con todo eso, no logró superarse el desequilibrio entre la oferta profesionalizante y la demanda empresarial, de modo que nuestras instituciones de educación superior se hallan desvinculadas del desarrollo social y, unas más que otras, constituyen organizaciones anacrónicas, con un completo agotamiento de su función profesionalizante (nótese que todavía la calidad universitaria se mide exclusivamente mediante la relación entre ingresos y egresos de estudiantes).

El panorama resulta aun peor si se considera que los contenidos curriculares que funcionan como motor de la profesionalización casi siempre son importados de los grandes centros de investigación de los países desarrollados y vienen empaquetados en libros y manuales de las grandes editoriales universitarias (McGraw-Hill, serie Schaum, Brooks/Cole, Eudeba, etc.). Muy raras veces el curriculum incluye contenidos derivados de investigaciones criollas. Y, para colmo, dichos contenidos suelen ser transmitidos dogmáticamente, sin mostrar que todos ellos son productos de la 
investigación científica y ocultando el proceso investigativo que los generó. De ese modo, la función profesionalizante no sólo se impone groseramente, sino que anula la función investigativa, de donde se deduce que nuestras institu-ciones universitarias no merecen el término Academia, simplemente porque están lejos de serlo (obviamente, tampoco nosotros merecemos el calificativo de académicos; menos que eso, somos más bien entrenadores o instructores).

Esto tiene muchas implicaciones. Una de ellas es que las organizaciones de educación superior se convierten así en el más fino instrumento de dominación y subdesarrollo, ya que toda dominación comienza por los conocimientos y tecnologías: el perfil de nuestros egresados de tercero, cuarto y quinto niveles no responde a nuestras realidades latinoamericanas sino a realidades extranjeras. No manejan cuerpos de experticias que resuelvan los problemas de nuestros propios países 0 , dicho al revés, tratamos los problemas de nuestros países como si fueran los problemas de aquellos países extranjeros de los cuales importamos los esquemas de experticias. Nos convertimos así en sociedades controladas desde afuera, por vía de las instituciones de educación superior, aliadas al constante bombardeo de los grandes medios masivos de comunicación (no es casualidad que en los países donde recientemente surgen gobiernos de izquierda, aunque ello no pase de las apariencias, sean precisamente las universidades las más fuertes opositoras, al lado del alto clero, de los países invasores, de los estratos más pudientes y el pensamiento mezquino en general).

Otra implicación es el desperdicio de los resultados de nuestras propias investigaciones. Ni siquiera existe un mecanismo institucional que esté atento a la captación de contenidos provenientes de las investigaciones nacionales y que permita su flexible incorporación al curriculum. Mientras esto continúe así, jamás podremos hablar con propiedad de interacción Docencia-Investigación ni de docente-Investiga- dor. Por otra parte, se desperdicia también cualquier tipo de conocimiento de tipo popular o no-certificado, aquel que nace y se maneja en comunidades de campesinos, obreros y creadores populares, por ejemplo, buena parte del cual ha demostrado tener tanta calidad como el conocimiento certificado (véase García-Lobo, 2008).

La superación de esta dificultad está en un cambio radical en la función de la educación superior, en sustituir su función profesionalizante por una función investigativa, de manera que esas instituciones apunten sustantivamente a la producción de los conocimientos y tecnologías que requiere el desarrollo nacional. Esto comenzaría por darle otro perfil a la función de extensión, convirtiéndola en un puente hacia el entorno social, un puente de ida y vuelta que detecte aquellas necesidades sociales que pueden ser resueltas por la producción científica y tecnológica, que las entregue a la función de Investigación y al final, una vez listos los productos, los consigne a los respectivos núcleos de demanda social y de conducción del desarrollo, ubicados en el entorno. La función de Docencia, por su parte, también se alimentaría de esos mismos productos investigativos y los diseños curriculares estarían constante y flexiblemente abiertos a los contenidos generados por la investigación (para más detalles acerca de este esquema véase Olivares de Quintero, 2001). Con esto la profesionalización estaría cubierta bajo los alcances de extensión e investigación y no se orientaría ya a los requerimientos empresariales sino a las demandas de desarrollo social directamente. Otra cara distinguiría así a nuestras organizaciones de educación superior, las cuales vivirían de su contacto con el entorno y con las necesidades de las grandes masas.

\subsection{La concepción curricular de la investigación}

Como consecuencia del carácter profesionalizante de nuestras "academias" (nótese la contradicción entre lo profesio- 
nalizante y lo académico: un "oxímoron", dirían los filólogos), ocurre que la investigación pertenece al curriculum, es engullida por éste y queda atrapada en el aula por las clases de metodología y los seminarios de investigación o de "proyecto", dirigidos a menudo por profesores que rara vez investigan.

La investigación no es conducida desde el seno de la misma actividad de los investigadores del área, sino desde el departamento de metodología de la investigación o del eje curricular de investigación, en total desconexión con los estándares de trabajo propios del área disciplinaria. Es decir, no es un ingeniero el que dirige las investigaciones en ciencias de la ingeniería, no es un biólogo el que administra el aprendizaje de la investigación en biología, no es un psicólogo el que está al frente de la enseñanza de la investigación en psicología, etc., sino un supuesto "metodólogo" que sólo se interesa en "metodología", como si ésta fuera indiferentemente aplicable a cualquier cosa, como si fuera un aparato formal independiente del contenido empírico y teórico que se maneja.

Se ha llegado en algunos casos hasta el absurdo de crear dos perfiles distintos: el asesor de contenido y el asesor metodológico, como si los verdaderos expertos en las distintas disciplinas nunca se hubieran enterado de los patrones de investigación utilizados en su respectiva disciplina, como si esos expertos se hubieran siempre dedicado a asimilar pasivamente los contenidos desarrollados en su área sin preocuparse por los patrones investigativos que subyacen a tales contenidos. No existe ningún experto en un área que al mismo tiempo no sea investigador en esa área, a menos que no sea un auténtico experto sino un memorizador mecánico. Pero, al suponer que la metodología va por un lado y el contenido investigativo por otro, se está suponiendo también que los contenidos son exclusivamente unos objetos de memorización o asimilación y no de producción. Se está suponiendo también que todas las ciencias actuales se han desarrollado sobre la base de una misma metodología, cuando cualquiera sabe que a lo largo de la historia de la ciencia buena parte de las variaciones en los patrones de trabajo se han producido justamente por ciertas exigencias típicamente asociadas al contenido empírico y teórico de cada disciplina. Casi todos nuestros estudiantes son testigos del efecto desconcertante de esa separación entre el asesor de contenidos y el asesor metodológico, los cuales, por cierto, raras veces están de acuerdo en algo, con las nefastas consecuencias para el tesista, que es al final quien carga con la peor parte. $Y$, por si fuera poco, entonces lo tildan de enfermo, ya que muestra el "síndrome TMT" y por tanto requiere de alguna terapia. Es esta estructura de desvinculación entre el componente metodológico y los contenidos disciplinarios lo que explica varias situaciones perversas en la práctica cotidiana. Por ejemplo, es por eso por lo que es desaprobado un proyecto para la construcción de un elevado en la carrera de ingeniería por el hecho de que el tesista no formula hipótesis (caso real) o de que otro proyecto en desarrollo de software también sea desaprobado porque falta el mapa de variables (otro caso real). En fin, abundan los casos reales de este tipo.

Predominan las recetas metodológicas y los esquemas preelaborados para la formulación de proyectos y desarrollo de trabajos de grado. Por ejemplo, en muchas instituciones exigen como "proyecto" de investigación los primeros tres capítulos del trabajo de grado o de la Tesis, que es aproximadamente lo mismo que si usted le encargara un diseño de remodelación a un arquitecto y éste se apareciera con un camión de bloques, cemento y arena, todo listo para cambiar la casa, sin que usted hubiera aprobado antes el diseño. Se confunde así plan con ejecución. Pero lo peor es que ya los nombres de los capítulos del trabajo de grado están previstos e incluso los títulos de las secciones y subsecciones: 
capítulo 1, el problema; capítulo 2, el marco teórico; capítulo 3 , la metodología..., y así, sucesivamente.

Si examinamos el caso de los postgrados, vemos cómo las llamadas líneas de investigación suelen reducirse a simples agrupaciones temáticas, pero no se cohesionan entre sí los trabajos individuales en términos de una agenda programática colectiva que considere relaciones globales de secuencia y complementariedad a diferentes plazos. La única utilidad del concepto de "línea de Investigación" está en sus posibilidades de funcionar como agenda o programa, algo así como decir: "tenemos tal o cual problema y, como grupo o comunidad académica, nos proponemos enfrentarlo y resolverlo dentro de $n$ años, bajo tal o cual esquema de progreso". Pero, en lugar de eso, lo que tenemos es, muy en general (hay excepciones), algo similar a los clubes sociales universitarios o a los renglones temáticos de una enciclopedia.

En general, los diseños curriculares de los postgrados le asignan más importancia a la llamada carga académica que al trabajo de grado. Las asignaturas, seminarios y demás actividades no suelen responder a los intereses de las tesis y parecen ser concebidos en total desarticulación entre sí y con respecto a dicha tesis. En ese sentido, la mayoría de nuestros doctorados tienen un matiz decididamente curricular, en detrimento de los estándares investigativos en la mayoría de las concepciones internacionales de los programas doctorales. En ciertos países uno oye cosas como "voy a hacer mi doctorado con el Dr. Fulano de Tal" o "hice mi doctorado con el grupo de Investigación Z" o "¿Sobre qué hizo usted su tesis?". Pero nunca se oye "¿en qué hizo usted su doctorado?". Esto remite a una concepción del doctorado estrictamente basada en la idea de investigación, orien- tada a la tesis doctoral y jamás a un conjunto de asignaturas y seminarios. Mayoritariamente, en los países desarrollados se plantea para los egresados doctorales un perfil de líderes de grandes programas de investigación, de modo que, inmediatamente después de culminada su tesis, se preparan para ese liderazgo mediante un postdoctorado, cuya función, lejos de responder a vanidades personales, es precisamente la de servir para esa transición entre los logros de su tesis y el ejercicio del liderazgo investigativo marcado por la ruta de esos logros. En nuestros países, en cambio, una vez que alguien culminó su doctorado, puede ocurrir que inmediatamente se le coloque en cargos de conducción investigativa, cuando en realidad todavía necesitan algún tiempo de maduración ${ }^{3}$. En general, internacionalmente, los postdoctorantes son personas jóvenes que se inician en el liderazgo de la investigación después de haber culminado su doctorado, pero no adultos mayores que aspiran a vanidades personales y que prefieren ostentar un pseudotítulo de postdoctor (título que no existe, pero que los vanidosos pretenden imponer ${ }^{4}$ ) antes que ceder generosamente sus conocimientos a los demás. En nuestros países subdesarrollados, en cambio, los programas doctorales de corte curricular parecen apuntar simplemente al logro de un título que permita aumentar los ingresos mensuales de los interesados (hubo una cierta universidad privada en la que en un tiempo se hablaba del doctorado como inversión: sobran los comentarios).

Consideremos ahora las implicaciones curriculares de la enseñanza de la investigación basada en manuales y textos de Metodología (cada año se multiplica la edición de manuales de ese tipo, repitiendo siempre los mismos errores con estructuras discursivas superficiales distintas). Como se sabe,

\footnotetext{
${ }^{3}$ Esto resulta aún más alarmante cuando los comités de admisión para cursos de postgrado están integrados por recién graduados: casi invariablemente se comportan según el complejo del mostrador (ver más adelante) y suelen sentir un placer especial cuando humillan a los participantes. Es todo un caso para una posible Psicología de la Academia.

${ }^{4}$ Hace poco me encontré con un antiguo estudiante mío, y cuando le pregunté si había terminado su doctorado me respondió que no sólo lo había terminado, sino que era "postdoctor". También supe de un profesor que, al firmar documentos, antecede a su nombre la sigla "PostDr.". Se infiere que nuestros postdoctorados son inútiles si ni siquiera son capaces de poner a las personas en su justo lugar ni de instruirlas acerca de lo que es un título académico.
} 
la enseñanza impartida desde esos manuales tiene carácter ex auctoritate, es decir, las operaciones de investigación son las que se dice que son y deben ejecutarse del modo en que se indica, siempre en virtud de la autoridad del autor del manual (magister dixit), pero muy raras veces se apoyan en muestras y casos de la historia de la ciencia y, mucho menos, en argumentos epistemológicos y en razonamientos desde una teoría de la investigación. Sería interesante un estudio que indagara cuánto han investigado los autores de esos textos, cuánto se dedican activamente a la producción académica, para así tener un panorama más completo de la enseñanza de la investigación basada en esos manuales. En un estudio de hace cuatro años, Camacho y Fontaines (2004) analizaron 60 manuales de este tipo, publicados entre 1952 y 2002 , y encontraron, primero, que apenas un $2 \%$ de ellos incluye esquemas operativos propios del enfoque epistemológico racionalista-deductivista (RD, arriba). El resto de los manuales estudiados (98\%) les enseña a nuestros estudiantes que sólo hay dos formas de trabajo investigativo: las que se derivan del enfoque empirista-inductivista (EI, arriba), o sea, la investigación medicional-probabilística, y las que se derivan del enfoque vivencialista-interpretativista (VI, arriba), o sea, la llamada investigación cualitativa. Con esto están afirmando que grandes investigadores como Einstein, Chomsky y Mendeleiev, por sólo citar tres, en realidad no fueron investigadores ni sus patrones de trabajo son dignos de ser considerados en la enseñanza de la investigación. En segundo lugar, los autores citados encontraron que en ninguno de los manuales se hace referencia a argumentos epistemológicos que apoyen lo que se prescribe. En realidad, esos textos suelen ser prescriptivos, pero no argumentativos. Le muestran al lector lo que debe hacerse, pero no le explican por qué. La gran mayoría de los textos de metodología muestra un total desprecio o desconocimiento por una Teoría de la Investigación que soporte sus enseñanzas y ni siquiera suelen apoyarse en casos representativos, ilustradores, tomados de la historia de la ciencia. En mi ac- tividad de tutor de tesis, a modo muy personal, siempre les recomiendo a mis tesistas abandonar toda consulta a los manuales de metodología y centrarse en el estudio de la epistemología y de la historia de la ciencia. No les recomiendo que regalen o vendan esos libros para evitar que hagan daño a terceras personas, pero sí que desconfíen de su lectura y que estén atentos a sus desaciertos. El tiempo que podrían dedicar a su lectura resulta mucho mejor invertido si lo dirigen a los documentos de filosofía de la ciencia, de teorías de la investigación, de epistemología y de historia de la ciencia.

El fondo del asunto está en que la enseñanza de la investigación está controlada por el curriculum y, por tanto, se pretende que nuestros estudiantes aprendan a investigar del modo menos directo posible y en el ambiente menos propicio para ello: el aula de clases. En realidad los investigadores se forman al lado de los buenos investigadores, en un ambiente en que se vean nacer y culminar muchos trabajos de investigación y en que el estudiante comience ensayando sus propias investigaciones, practicando, observando y pensando. Al lado de esa práctica junto a expertos, los investigadores se forman mediante el estudio de la epistemología, de las teorías de investigación, de modo que su aprendizaje vaya acompañado por argumentos de fondo que justifiquen y apoyen sus progresos e intentos. El estudio de casos sería un importante recurso adicional. Pero centrar la enseñanza de la investigación en el aula de clase es como formar futbolistas en una sala de te, por ejemplo, mostrándoles fotos del balón y del terreno y prescribiéndoles instrucciones verbales sobre cómo pasarse el balón hasta llegar al arco del competidor, pero sin ponerlos en contacto con buenos futbolistas ni con teorías del juego y ni siquiera con el balón.

No voy a detallar aquí las perversiones relacionadas con jurados, evaluadores, defensas de trabajo de grado y demás procesos de la inquisición curricular al mejor estilo de Tor- 
quemada, porque son harto conocidas y de ellas la inmensa mayoría de nosotros ha sido su víctima al menos una vez. Sólo apuntaré un aspecto central.

Este aspecto se refiere a dos actitudes opuestas entre los evaluadores de investigación: la actitud obstructiva, hostil, y la actitud colaborativa, amigable. En la primera actitud tenemos a aquellos evaluadores (jurados, asesores, profesores de metodología, miembros de comités académicos...) que no sienten la más mínima curiosidad ni el más mínimo interés por aprender algo de un proyecto o de un trabajo de grado. No, porque ellos se sienten evaluadores y no aprendices, sienten que su papel es el de castigadores y sancionadores, sienten que su prestigio se diminuye si no encuentran fallas en un trabajo o si preguntan algo que no entienden o de lo que no saben; sienten, en fin, que todo trabajo de los estudiantes es esencialmente malo. De allí esa costumbre tan generalizada en nuestras instituciones de tachar como "malo", o "mal formulado" o "mal planteado" cualquier elemento de un trabajo, sin decir cómo corregirlo, cómo mejorarlo. Estamos tristemente acostumbrados a oír expresiones gratuitas, no sustentadas, del tipo de "ese trabajo no sirve", "ese objetivo está mal formulado", "ese problema no se entiende", etc., pero siempre sin sugerirle opciones al estudiante, sin recomendarle cómo reajustar el punto. Lo que ignoran quienes tienen esta actitud es, aplicando aquello de error tipo I y error tipo II en teoría de la investigación e hipótesis probabilísticas, que mucho más riesgo se corre cuando nos equivocamos al rechazar un buen trabajo por considerarlo malo (error tipo I o tipo) que cuando nos equivocamos aceptando un mal trabajo por considerarlo bueno (error tipo II o tipo). Esto lo saben muy bien quienes investigan en el área farmacológica y médica, pero no parecen saberlo nuestros evaluadores de investigación social. Para ellos, el estudiante debe defender su tesis, lo cual implica que va a ser atacado. Luego, en lugar de hablar de defensa de tesis podríamos simétricamente hablar de ataque a la tesis, así que cuando le preguntamos a alguien "¿cuándo defiendes tu tesis?", igualmente podríamos preguntarle "¿cuándo te atacan tu tesis?". Y el contenido discursivo de esas preguntas sería, objetivamente, el mismo.

En la segunda actitud tenemos a los evaluadores colaboradores, amigables, aquellos que prefieren cometer el error tipo II al juzgar las investigaciones (prefieren equivocarse al considerar como bueno un trabajo malo antes que equivocarse descartando como malo un trabajo que es bueno). Son los que están conscientes de que no hay trabajo malo que no pueda ser convertido en un trabajo bueno (excepto los plagios, que no pueden ser considerados ni tolerados bajo ningún respecto). Están conscientes de que la calidad de los trabajos se puede incrementar a través de reelaboraciones sucesivas y de nuevas versiones progresivamente reajustadas, pero siempre bajo orientaciones colaborativas. Son los que están conscientes de que el ser humano es sustancialmente ignorante, de que, por tanto, ellos mismos nunca dejarán de aprender y de que, en consecuencia, puede ser mucho lo que se aprovecha de un proyecto o una investigación de cualquier estudiante. Todo esto pinta un panorama radicalmente distinto frente a las posibilidades de crecimiento de una investigación social orientada al desarrollo. Desde el ángulo de esta actitud constructiva y colaborativa, estamos obligados a promover las investigaciones, no a sancionarlas. Podemos criticar los trabajos, podemos estar en desacuerdo con ellos, podemos quejarnos de ellos, pero, eso sí, siempre estaremos dispuestos a proveer estrategias y opciones de reajuste, de mejoramiento, siempre estaremos dispuesto a colaborar. Con lo que se está en desacuerdo es con los trabajos que no están abiertos a la crítica, al mejoramiento y a la reelaboración, aquellos que se consideran excelentes a primera versión, sin antes considerar las críticas y las sugerencias de reajuste. En suma, de lo que se trata es de progresar, de incrementar la cantidad y calidad de nuestras investigaciones, siguiendo aquel postulado de Popper de 
que aprendemos y producimos conocimiento bajo el esquema del ensayo-y-error (véase al respecto un interesante artículo sobre las implicaciones educativas de este postulado popperiano en Halliday, 1999). Pero, para los efectos, deberíamos erradicar esta concepción curricular en función de que todo esto sea posible. Mientras mantengamos esa visión curricular, esa visión de que todo se centra en el aula de clases y en las asignaturas, de que todo depende de un diseño curricular que todo lo engulla, nunca lograremos tales progresos.

Finalmente, para concluir esta sección, en la cual habría mucho más que decir, consideremos los documentos institucionales que conceptualizan el trabajo de grado en nuestras instituciones. En casi todo ellos se lee que la función del trabajo de grado es "demostrar competencias metodológicas para la investigación". Es decir, nuestras instituciones consideran que los trabajos de grado no son investigaciones sino tareas escolares, demostraciones de que se logró un objetivo instruccional. Una visión más curricular, más estrecha que esa, es imposible.

\subsection{Las alcabalas de la Burocracia como freno a la Investigación}

En dos trabajos anteriores detallé el nefasto papel de la burocracia universitaria en asuntos académicos (Padrón, 2004a y 2005). Mi tesis general es que en las organizaciones de educación superior interactúan cuando menos dos factores: uno es sustantivo, central, esencial, que es el conocimiento, el contenido académico, en flujo constante por todo el sistema, y otro es logístico, de apoyo, vehicular, que es el aparato burocrático. A modo de ilustración, podríamos imaginarnos el aparato burocrático como una red de carreteras, avenidas, calles y autopistas que interconectan varias poblaciones y en las cuales hay semáforos, alcabalas, puntos de control, peajes, etc., junto con el conjunto de personas asociadas a esos elementos (policías, guardias, vigilantes, técnicos, secretarias, etc.).

Y podemos imaginarnos el conocimiento o el contenido académico como los automóviles que circulan por toda esa red. Podemos suponer que el trayecto recorrido por cada automóvil desde su punto de salida hasta su punto de llegada genera algún tipo de producto del gran sistema. Lo sustantivo, entonces, está en esos trayectos generadores de productos del sistema. El sistema será más o menos eficiente, o sea, tendrá una alta o baja productividad en la medida en que esos trayectos resulten relevantes y cumplan el flujo previsto. Pero para esto es indispensable que las vías estén en buen estado, que se adecuen al tipo y volumen de flujos, que las alcabalas controlen el cumplimiento de las normas, que los semáforos racionalicen las diferencias de trayectorias, etc. Lo central es el flujo que genera productos válidos, pertinentes y relevantes; ese es el aspecto sustantivo del sistema, mientras que lo periférico es el aparato de recursos, servicios y utilidades del sistema.

Aproximadamente lo mismo ocurre en una organización universitaria: lo sustantivo es el conocimiento o el contenido académico que circula de un punto a otro del sistema en una trayectoria de transformación de productos. $Y$ lo servicial, lo utilitario, es el aparato burocrático. El sentido, la razón de ser de este aparato burocrático viene marcado por las necesidades, las condiciones y las características del contenido académico, de modo que este aparato debe estar en constante atención y mejoramiento para servirle mejor al flujo de contenido académico, para que este flujo sea cada vez más rápido, más cómodo, con menos trabas. Y aquí hay algo clave: el aparato utilitario, servicial, es decir, el aparato burocrático, sólo atiende a la eficiencia de los flujos, pero jamás a la validez, pertinencia y relevancia de los contenidos académicos. Cuando el factor burocrático toma para sí mismo esas atribuciones, ocurren las perversiones organi- 
zacionales de las academias. Cuando el mecanismo burocrático se roba el derecho a decidir sobre la calidad de los contenidos académicos, ocurre un secuestro de la función sustantiva de la organización. Es el primer síntoma de una mortífera enfermedad. Éste sí puede metaforizarse como un "síndrome". Volviendo a la comparación anterior, es como si los fiscales de una alcabala, al pasar un cargamento de patillas o de naranjas, por decir cualquier cosa, se dedicaran a examinar la calidad de las frutas y a castigar o detener al conductor en caso de que ellos consideraran que la carga no cumple los estándares de calidad. Sería una perversión, ya que las decisiones sobre calidad de los productos son parte esencial de la misma estructura sustantiva de productividad, no de los aparatos utilitarios y de servicio.

Si el sistema es sano, el aparato burocrático siempre funcionará como estructura de utilidades y servicios y también de control vehicular y de racionalización del flujo de contenidos académicos. Ese aparato, así concebido, incrementará la productividad académica en un sistema sano. Pero si el sistema es perverso ocurrirá lo contrario. O, mejor dicho, cuando no ocurre eso, el sistema se pervierte.

¿Y por qué se pervierte el sistema? ¿Qué hace que se trastoquen los papeles? La respuesta es compleja y resulta difícil exponerla brevemente. Pero hay algo central: la validez, legitimidad y relevancia del contenido académico es una decisión interna de esos mismos procesos académicos, jamás del aparato burocrático. La perversión viene no sólo cuando el aparato burocrático invade funciones académicas, sino cuando el mismo aparato académico se convierte en mecanismo burocrático: a falta de capacidades académicas se abrogan facultades burocráticas.

El freno a la cantidad y calidad de la investigación social tiene lugar cuando los evaluadores ignoran casi todo sobre los procesos investigativos y entonces, para compensar esa carencia, ejercen todo su poder de alcabala, toda su fuerza burocrática sobre los tesistas e investigadores en general. A cambio de su aprobación, piden sumisión, respeto y, a veces, algo material también. En un documento anterior escribí eso mismo, llamándolo el "complejo del mostrador" (Padrón, 1999):

La metáfora radica en la imagen del pequeño empleado ubicado detrás de un mostrador o taquilla de atención al público, el cual llega a sentirse grande y omnipotente cuando ve que en sus manos está la solución del problema de algún cliente o usuario, problema que en sí mismo podría resultar cotidiano y banal, pero que, para el usuario y según las circunstancias, llega a convertirse en delicado y crítico (abordar el avión estando en una lista de espera, conseguir una entrevista de importancia, ser exonera-do de una multa...). Entonces, de empleado subalterno y mal pagado, el individuo llega prácticamente a comportarse como un dios ante el desesperado usuario, ejerciendo toda una relación de dominación, aunque sólo sea circunstancialmente. Junto a algunas secretarias, oficiales de tránsito, empleados de lí-neas aéreas, etc., también algunos docentes son descritos por el "complejo del mostrador," especialmente cuando se trata de cosas como aprobar un proyecto de tesis $u$ obtener una calificación.

Pero no son sólo las secretarias ni los fiscales de tránsito ni, en general, los empleados de baja categoría, sino que muchos rectores, vicerrectores, decanos, miembros de comités académicos, jurados, etc., tienden a ser la representación más evolucionada y sofisticada de ese complejo del mostrador. Son todavía peores que los humildes oficiales de tránsito. Ese complejo del mostrador en realidad es la base de la perversión de la Burocracia, algo así como su génesis: cuando el burócrata se da cuenta de ciertas oportunidades de poder, entonces no sólo la ejerce, sino que la refina, la 
consolida y la convierte en todo un sistema de dominación que tiende a crecer y a engullir cada vez más, con un hambre insaciable.

Un modo de superar esto es exigir a los evaluadores de investigaciones un profundo dominio de los procesos investigativos y, en especial, un total manejo de los enfoques epistemológicos. No debería permitirse que fueran miembros de jurado o de comités académicos o de selección o de decisión aque-llos que no son investigadores activos y que no han realizado al menos unas cinco $u$ ocho investigaciones publicadas y reconocidas. Lamentablemente, sólo se exige que tengan el mismo nivel del autor que está siendo evaluado y es por ello que vemos fungir de evaluadores a profesores que en toda su vida apenas han hecho algún trabajo de ascenso o algún trabajo de grado, pero que en realidad no son investigadores ni tienen conocimiento epistemológico alguno. Es así como, para compensar su ignorancia académica, recurren al chantaje burocrático, con lo cual se desmejora notablemente la producción de investigaciones sociales orientadas al desarrollo. Es todo un espectáculo revisar muchas de las observaciones que los evaluadores burócratas hacen a los trabajos: tachaduras con la anotación "esto está mal formulado" o signos de interrogación que no dicen nada o subrayados con signos de admiración que tampoco dicen nada. Sé del caso de un evaluador que en todas las páginas del trabajo de una profesora anotaba lo siguiente: "¿quién dijo esto?". Como esa leyenda aparecía absolutamente en todas las páginas del trabajo (a mitad del mismo ya sólo escribía las iniciales: "¿y q d e?"). Es de suponer que ese evaluador estaba convencido de que en una investigación no se puede decir nada original, sino que todo debe tomarse de alguien que ya lo haya dicho antes, o sea, investigar es repetir cosas ya dichas. Parece que la eliminación de la burocracia y de los burócratas en nuestras instituciones es algo que debe hacerse urgentemente.
Quedan muchos otros obstáculos organizacionales por mencionar, tales como la falta de definición de preferencias investigativas en el nivel institucional, la desarticulación de los esfuerzos individuales, la ausencia de una cultura de investigación, la concepción de la investigación sólo como proceso y no como producto, etc. Una exposición detallada de estos factores que aquí sólo se mencionan puede verse en Padrón (2001, 2004b y 2006).

\section{LOS OBSTÁCULOS EPISTEMOLÓGICOS}

Aquí se agrupan aquellos factores cuya potencia inhibidora depende de prejuicios, distorsiones y errores epistemológicos. Como se dijo arriba, la concepción curricular eclipsa las visiones epistemológicas, las que se arraigan en una teoría de la investigación, para imponer una visión metodológica per se, no sustentada teóricamente y de naturaleza prescriptiva (algo así como las recetas de cocina). Esta visión metodológica se ha ido construyendo a partir de cánones impuestos originalmente por algún autor de manuales de metodología y luego esos cánones se repiten y se difunden entre profesores, aseso-res, tutores y jurados, los cuales a su vez los imponen a los investigadores sociales y tesistas. Nadie los discute y nadie sabe qué fundamento tienen ni por qué se aplican. Es algo parecido al caso de una señora que cuando preparaba pernil siempre le cortaba un extremo antes de meterlo al horno. Al preguntarle por qué le cortaba ese pedazo respondió que no sabía, que así mismo hacía su madre. Al preguntarle a la madre, dijo lo mismo: no sabía y que así mismo había visto a su madre preparar el pernil. Y al ir donde la abuela para averiguar la razón, ésta explicó que en su época el horno que tenía era muy pequeño y, como no cabía el pernil entero, tenía que cortarle un pedazo. La hija y la nieta tenían en cambio un horno grande, pero por pura repetición continuaban haciendo lo mismo sin preguntarse por qué y creyendo que era parte de la receta. Veamos algunos de los factores de este tipo. 


\subsection{Universalización y particularización}

("ese tema es muy amplio, delimita")

Éste es uno de los factores más difundidos, no sólo en nuestro país sino en muchas otras partes. En realidad, es uno de los resabios del enfoque empirista inductivista $(R I$, el de los objetos observables) que dominó hasta no hace mucho y que solía basarse en inferencias a partir de muestras representativas de un universo. Entonces, al trabajar con muestras, particularizaban el diseño y lo reducían a la muestra (los estudiantes de una escuela, por ejemplo), pero mantenían su visión en el universo (el conjunto de todos los estudiantes, siguiendo con el ejemplo), hacia el cual proyectaban sus generalizaciones. Esto fue muy mal entendido por muchos profesores de metodología, quienes creyeron que también el problema y el objetivo de investigación debían particularizarse. Pongamos el caso de un tesista que formule un problema como qué factores intervienen en el rendimiento. Entonces algunos profesores le dirían que el tema es muy amplio, que delimite, qué precise cuáles estudiantes y en qué área de rendimiento va a investigar. El tesista termina reformulando su problema de un modo como éste: qué factores intervienen en el rendimiento en matemáticas en los estudiantes de la escuela $W$. Con eso la investigación bajó tremendamente sus niveles de socialización, ya que sus resultados sólo pueden aplicarse a los estudiantes de la escuela W, exclusivamente en el área de matemáticas y no a ningún otro estudiante en ninguna otra área. Si por cualquier circunstancia esa escuela desapareciera o fuera clausurada, desaparecería también el objeto de estudio y la investigación perdería todo sentido. Es decir, si el tesista hubiera querido formular una teoría del rendimiento jamás habría podido lograrlo porque no está considerando el objeto de estudio en sentido universal, abstracto, sino sólo para el caso de los de la escuela W. Y ya sabemos que una teoría del rendimiento en matemáticas en la Escuela $W$ no sería nunca una teoría científica, justamente por su escaso valor de socialización.

Pero eso no es todo. Además está el problema de la relevancia y de las clases universales: ¿hay alguna propiedad que haga particularmente diferentes a los estudiantes de la escuela W con respecto a los demás estudiantes? Es como si nos preguntáramos por qué los habitantes de Margarita tienen dos piernas. No son sólo los habitantes de Margarita los que tienen dos piernas. Todas las personas normales las tienen, de modo que se trata de una pregunta irrelevante. Dicen que Newton hizo sus observaciones y experimentaciones en el patio de su casa, pero cuando formuló sus tres leyes habló de "leyes del movimiento de los cuerpos" y no de leyes del movimiento de las piedritas del patio de mi casa. Claro, si Newton hubiera caído en manos de alguno de estos profesores, éste le habría dicho: ¿cuáles cuerpos? ¿en qué parte? Delimita el problema. Y, gracias a este profesor imaginario, jamás se habrían producido las leyes de Newton y la física habría frenado su desarrollo. Una de las máximas aspiraciones de la Ciencia es la formulación de teorías que expliquen clases universales de hechos y no clases particulares. Einstein, por ejemplo, se propuso diseñar una teoría del universo; Chomsky se propuso formular una teoría universal de los lenguajes (todos); Darwin, una teoría de las variaciones de los seres vivos (todos); Luhmann, una teoría de los sistemas sociales (todos); Mendel, una teoría de la herencia (no sólo de los guisantes de su huerto) y, así, muchísimos casos más. Algunos asesores y tutores les habrían dicho que cada uno de esos temas era muy amplio, que delimitaran el tema. Por suerte, eso no ocurrió en esos casos célebres, pero es fácil imaginar cuántos trabajos de investigación en nuestras instituciones, que pudieron haber sido excelentes, resultaron inhibidos por quienes confunden delimitación con particularización y por quienes no entienden la investigación teórica. 
Alguien podría decir que existen los estudios de casos, los cuales apuntan a clases particulares de hechos. Es cierto, los estudios de casos constituyen un patrón de trabajo sumamente útil y además están las investigaciones focales, ampliamente usadas en medicina, zoología y botánica, como, por ejemplo, un estudio de los insectos de los bosques secos de Guatemala o un estudio de las células de la superficie ocular en pacientes con aniridia, etc. Pero hay algo importante: los trabajos focales, los estudios de casos y, en general, todas las investigaciones empíricas, orientadas a clases particulares de hechos, se conciben, se entienden y se justifican siempre por relación con un programa de investigación amplio que les da cobertura en general a todos los casos y focos estudiados por los miembros del programa, de modo que, sumados todos esos estudios, se pretende llegar a una clase universal de hechos, es decir, a una teoría amplia. Y esto ocurre por la inseguridad científica acerca de la especificidad de cada caso y, en consecuencia, por el riesgo de asumirlos todos de antemano en una sola clase universal. Pero es absurdo un estudio sobre un conjunto reducido de hechos cuando de antemano se sabe que pertenecen a otro conjunto más amplio y cuando existen los mecanismos investigativos adecuados para tratarlos universalmente (por ejemplo, estableciendo condiciones de variación geográfica o histórica o social, etc.). En todo caso, debemos diferenciar entre investigaciones empíricas y teóricas. Las primeras están en función de las segundas y tienen sentido dentro de grandes programas de investigación en los que participan muchos investigadores y en los que se busca llegar sucesivamente a una fase teórica, mientras que las segundas pretenden siempre cubrir grandes clases de hechos y se valen de los resultados de las primeras (de allí la necesidad de evitar superficialidades al analizar el concepto de "Línea de Investigación"). Ya sabemos que los programas de investigación nacen con una fase descriptiva, pasan a una fase explicativa, se mueven luego hacia una fase contrastiva y cierran en una fase aplicativa o tecnológica. Lo que se critica aquí es que muchas veces, cuando un estudiante aspira a una investigación teórica, algunos profesores pretenden convertírsela en empírica, sin mayores análisis, sólo basados en el prejuicio de la delimitación del tema.

\subsection{Las hipótesis, las variables y la operacionalización}

Aunque este prejuicio ha cedido bastante con el reciente auge de la investigación basada en el enfoque vivencialistainterpretativista (VI, arriba), todavía en muchas partes sigue causando molestias. Consiste en dar por sentado que toda investigación debe tener hipótesis, variables, indicadores y operacionalización del problema, por sólo citar cuatro elementos discutibles. El problema de fondo está en pasar por alto las variaciones metodológicas originadas a partir de los enfoques epistemológicos y de la estructura diacrónica de los procesos de investigación (las fases de desarrollo de los Programas de Investigación).

Por un lado, tenemos que sólo dentro del enfoque inductivista-realista (medicional, probabilístico) se habla de variables e indicadores y se suele operacionalizar el problema, pero nunca en el enfoque vivencialista-interpretativista y no siempre en el enfoque racionalista-deductivista. En el primero de estos dos se usan más bien las categorías de análisis y en el segundo las propiedades o predicados de un argumento. En cuanto a las hipótesis, es muy raro verlas en investigaciones Vivencialistas-Interpretativistas (donde tampoco se usa la operacionalización del problema ni los indicadores) y en el enfoque racionalista-deductivista tienen una naturaleza y una función totalmente distintas. Las hipótesis del empirismo-inductivista suelen ser de tipo experimental, divididas en hipótesis nula (no se encuentra dependencia entre variables o no hay diferencia significativa entre las medias poblacionales) y alterna (se encuentra esa dependencia, hay diferencia significativa de medias). Pero en el racionalismo-deductivista las hipótesis tienen un alto rango 
teórico y abstracto y sirven para derivar de ellas enunciados progresivamente más específicos, hasta llegar a enunciados observacionales que puedan ser puestos en comparación con los hechos. Nótese este concepto de Hipótesis en la siguiente cita de Einstein (1989):

Supondremos, por tanto, la completa equivalencia física entre un campo gravitacional y la correspondiente aceleración del marco de referencia. Esta hipótesis amplía el principio de la relatividad especial al caso del movimiento uniformemente acelerado del marco de referencia. EI valor heurístico de esta hipótesis está en que permite la sustitución de un campo gravitacional homogéneo por un sistema de referencia uniformemente acelerado, siendo este último caso, hasta cierto punto, accesible a un tratamiento teórico (p. 2. Trad. propia). ${ }^{5}$

Por otro lado, es sólo en las investigaciones explicativas (teóricas o empíricas) en las que cabe la formulación de hipótesis (en cualquiera de los dos sentidos que acaban de mencionarse de acuerdo al enfoque epistemológico), pero nunca en las demás fases del desarrollo de los Programas de Investigación. Por ejemplo, en una investigación descriptiva, que sólo busca las características que tiene un hecho u objeto (o sólo se buscan aquellos hechos u objetos que responden a determinadas características), allí no se puede suponer nada, no se puede adelantar hipótesis, simplemente se trabaja con herramientas observacionales y sistemas conceptuales hasta encontrar esas descripciones. Lo mismo ocurre en las investigaciones aplicadas o tecnológicas (en tecnologías tanto materiales como humanas), en las que se busca el diseño de una secuencia de operaciones e instrumentos que permitan intervenir una situación. Ahí tampoco se puede suponer nada: sólo se describe la situación que se desea intervenir y de ciertas teorías fecundas se deriva el diseño, muchas veces convertido en un prototipo debidamente validado. Nada que suponer ahí, ninguna hipótesis que adelantar, bajo ninguno de los enfoques epistemológicos, porque la idea es diseñar algo que resuelva una situación mejorable. Entre los casos célebres tenemos al Dr. Robert Adler, fallecido recientemente, quien inventó el control remoto a partir de la teoría de Einstein sobre el efecto fotoeléctrico: no hizo hipótesis, sino que, habiendo estudiado el trabajo por el que Einstein se había ganado el Nóbel (Adler era doctor en física) imaginó el diseño y construyó el prototipo de control remoto para TV.

El daño que se les hace a nuestros tesistas al exigirles estos elementos, sin considerar las condiciones que se acaban de explicar, se traduce especialmente en una gran confusión para comprender la lógica de los procesos de investigación. Difícilmente podremos formar investigadores si continúa este prejuicio.

\subsection{Los tipos de investigación}

Aquí es tal vez donde más se enredan nuestros tesistas, debido a las ineficientes clasificaciones que pululan en los manuales sobre investigación. En un trabajo anterior (Padrón, 2007), en que se critica el concepto de investigación exploratoria, está desarrollada esta idea de la ineficiencia de las clasificaciones de los trabajos de investigación, las cuales pecan de dos grandes fallas lógicas: la escasa independencia de las clases o tipos que se postulan y la poca relevancia de los criterios de clasificación. Toda clasificación, si se desea que sirva para resolver problemas, debe someterse a ciertos estándares lógicos en dependencia de un objetivo.

\footnotetext{
5 "We shall therefore assume the complete physical equivalence of a gravitational field and the corresponding acceleration of the reference frame. This assumption extends the principle of relativity to the case of uniformly accelerated motion of the reference frame. The heuristic value of this assumption rests on the fact that it permits the replacement of a homogeneous gravitational field by a uniformly accelerated reference system, the latter case being to some extent accessible to theoretical treatment."
} 
Uno de estos estándares es que los criterios a partir de los cuales se forman clases o tipos sean relevantes, significativos, que sean útiles para discriminar las cosas en función de un objetivo de trabajo. El objetivo de trabajo, el problema que se quiere resolver es, en este caso, orientar al investigador a discriminar entre los múltiples caminos amplios que tiene por delante cuando se dedica a una investigación. Para las instituciones y para los Programas de Investigación, el objetivo es el de organizar los esfuerzos culminados y planificar sus agendas. En consecuencia, nuestras clasificaciones de investigaciones deben ayudar a lograr ese objetivo. Si una clasificación no ayuda a resolver ese problema, a lograr ese objetivo, entonces no es una clasificación eficiente.

Pongamos un caso extremo: supongamos que queremos clasificar a los seres humanos porque deseamos producir un fármaco para reducir la obesidad. ¿Clasificaríamos a los seres humanos bajo el criterio de la talla de calzado, postulando, por ejemplo, tres clases o tipos: los de pie grande, de pie mediano y de pie pequeño? No, porque ese criterio es irrelevante con respecto al objetivo planteado, es un criterio que apunta a un insignificante detalle y no a algo sustantivo en relación con el problema que queremos resolver. Mucho más relevante sería el criterio Peso/Estatura/Masa o Perímetro abdominal, con clases como alta, media y baja o cualesquiera otras clases que desagreguen el criterio seleccionado. Ese es, aproximadamente, lo mismo que ocurre con una clasificación muy difundida, que discrimina los trabajos de investigación bajo el criterio de la fuente de los datos utilizados: "de campo", "documental" y "experimental". Ese criterio nos dice tan poco acerca de una investigación, está limitado a un paso tan específico del trabajo investigativo (como es la recolección de datos), que no ayuda en nada al objetivo de que el investigador elija un camino adecuado a sus intereses. Mucho más productivo es el criterio de la intención de trabajo o de la fase diacrónica en la trayectoria de desarrollo de un Programa de Investigación. El tesista sí aclararía sus tomas de decisión si discrimina entre describir una cierta clase de cosas o, en cambio, explicar qué clase de cosas es responsable de otra o, en cambio, contrastar, validar o falsar una teoría preexistente o, en cambio, diseñar una aplicación o crear una tecnología que mejore alguna situación humana.

¿Por qué este criterio sí resulta relevante para el objetivo señalado? Simplemente porque está vinculado a una fase sustantiva, principal, aguas arriba, del proceso investigativo: el problema y los objetivos de trabajo, de lo cual se deriva toda la estructura completa de su investigación, más todo la heurística requerida para llevarla a feliz término, nada de lo cual se obtiene con el criterio de la fuente de los datos ("documental", "de campo", "experimental", etc.).

Es más: el criterio de la fuente de la recogida y tratamiento de datos depende estrictamente de la intención de trabajo, así que discriminar entre "documental", "de campo" y "experimental" es algo que está muy aguas abajo de describir, explicar, contrastar y aplicar. Podría demostrarse lógicamente que el criterio de la fuente de los datos, dado un árbol jerárquico de operaciones de investigación, está mucho más abajo que la intención de trabajo y, por tanto, está incluido en ésta.

Conclusión: es irrelevante discriminar los trabajos de investigación según la fuente de los datos y según la técnica de recogida y tratamiento de dichos datos. Aparte de eso, una vez más, en nuestra cultura investigativa dominante quedan excluidas las investigaciones concebidas bajo la perspectiva racionalista-deductivista, a la cual le importan más las estructuras deductivas que los datos y las recogidas de datos. Es típico de esta clase de investigaciones esforzarse muy poco en los datos y, en casi todos los casos, el trabajo de campo es menos importante que el trabajo teórico. Pero ocurre que tampoco puede decirse que hacen trabajo docu- 
mental ni, mucho menos, experimental, porque la clave de su éxito está en pensar e imaginar. ${ }^{6}$ Todo esto queda excluido de los manuales de metodología de la investigación, en los cuales sólo se prescribe acerca de investigaciones "de campo", "experimentales" o "documentales o entre investigación cuantitativa e investigación cualitativa. Este es un punto de vista muy pobre que incide negativamente en la formación de investigadores sociales.

Otro criterio que se pasa por alto, y que ocurre en la misma entrada de las variaciones de los procesos de investigación, es el de los enfoques epistemológicos. Se trata de un criterio grueso que prevé los múltiples caminos a que se enfrenta el investigador desde el mismo inicio de su tarea, mucho antes de que pueda pensar en la fuente de sus datos observacionales, lo que significa que sí es un criterio clasificatorio de primer nivel. La selección del enfoque epistemológico es un discriminador tan potente y tan influyente en todo el proceso operativo que, como quien se sienta frente al mapa de una ciudad desconocida, es lo que determina primariamente la escogencia de un cierto tema de investigación y de un determinado problema. En efecto, preguntémonos por qué a Newton no le interesó trabajar sobre psicología ni sociología, sino sólo sobre el movimiento, sobre las leyes que regulan el movimiento de los cuerpos. Preguntémonos por qué a nuestros estudiantes los atraen ciertos temas de tesis y no otros. La respuesta está en las nociones de Estilos de Pensamiento y de enfoques epistemológicos. Las personas eligen sus temas de interés sobre la base de la predominancia de un cierto estilo de pensamiento y los investigadores seleccionan sus problemas y objetivos de trabajo sobre la base de un determinado enfoque epistemológico predominante. Decir que es el tema o el problema de investigación lo que remite a un cierto tratamiento epistemológico y metodológico equivale a decir que todas las personas por igual desarrollan exactamente el mismo interés ante cualquier tema. Equivale a decir que todos, sin distinción, pudimos haber sido ingenieros, sacerdotes o filósofos, indiferentemente. Si así fuera, sobrarían las pruebas de aptitud vocacional, las cuales, aunque no se diga, obedecen a la noción de estilos de pensamiento. Y, en materia de investigación científica, el enfoque epistemológico no sólo es anterior a cualquier planteamiento investigativo, sino que además condiciona tanto el mismo planteamiento como sus posibles modalidades de desarrollo. Esto es lo importante: que los tipos de investigación dependen primariamente del Enfoque Epistemológico, el cual regula toda la estructura global del trabajo y la selección de todos los demás niveles operativos, entre los cuales la fuente de los datos observacionales (documental, de campo, experimental) es uno de los más bajos e irrelevantes. En la tabla 1 se quiere mostrar cómo el enfoque epistemológico orienta toda la estructura global de las investigaciones.

Luego de ese nivel, el criterio que le sigue en importancia es el de la intención de trabajo, como se dijo arriba, que puede examinarse en correlación con las fases de desarrollo diacrónico de los programas de investigación, las que a su vez se correlacionan con las fases de desarrollo cognitivo de los niños: ${ }^{7}$ descripciones, explicaciones, contrastaciones, aplicaciones. La unión de estos dos criterios del más alto nivel conceptualizador se representa en la tabla 2, donde en las columnas aparecen las intenciones de trabajo, en las filas aparecen los enfoques epistemológicos y en las celdas están los distintos patrones de trabajo derivados del cruce de esos dos criterios.

6 En Internet en español aparece mucho esta cita de Einstein: "Cuando examino mis métodos de pensamiento llego a la conclusión de que mi don para la fantasía ha significado más para mí que mi capacidad de absorber el conocimiento positi-vo". Por "fantasía" quiere decir "capacidad de imaginación", que es esencial en el enfoque RD (es la célebre abducción de Peirce, que no es introspección, como muchos creen, sino Racionalismo o enfoque RD). Por "conocimiento positivo" se refiere a los datos observacionales. Otra cita confirmadora es ésta: "La realidad no es otra cosa que la capacidad que tienen de engañarse nuestros sentidos". Una de esas fuentes es http://www.literato.es/autor/albert_einstein/

7 Los niños, desde su nacimiento, comienzan con una fase descriptiva en la que buscan organizar el extraño mundo que los rodea (es típica la pregunta "¿qué es esto?"). Una vez saturada esa fase, pasan a una fase explicativa, buscando averiguar por qué las cosas ocurren del modo en que se ve que ocurren, con lo cual elaboran sus 


\begin{tabular}{|l|l|l|l|l|l|}
\hline ENFOQUE & NATURALEZA DEL CONOCIMIENTO & MÉTODO DE & MÉTODO DE & LENGUAJE & OBJETO DE \\
\hline $\begin{array}{l}\text { EMPIRISTA- } \\
\text { INDUCTIVO }\end{array}$ & $\begin{array}{l}\text { Representación de patrones de } \\
\text { regularidad o frecuencia. } \\
\text { El conocimiento es un acto de } \\
\text { descubrimiento. }\end{array}$ & Inducción & Experimental & $\begin{array}{l}\text { Aritmético- } \\
\text { matemático }\end{array}$ & $\begin{array}{l}\text { Relaciones } \\
\text { causa-efecto, } \\
\text { repeticiones de } \\
\text { eventos }\end{array}$ \\
\hline $\begin{array}{l}\text { RACIONALISTA- } \\
\text { DEDUCTIVO }\end{array}$ & $\begin{array}{l}\text { Modelación de procesos generativos. } \\
\text { El conocimiento es un acto de } \\
\text { invención. }\end{array}$ & Deducción & $\begin{array}{l}\text { Análisis } \\
\text { lógico-formal y y } \\
\text { experimental }\end{array}$ & $\begin{array}{l}\text { Lógico- } \\
\text { matemático }\end{array}$ & $\begin{array}{l}\text { Relaciones } \\
\text { entrada-pro- } \\
\text { ceso-salida }\end{array}$ \\
\hline $\begin{array}{l}\text { INTROSPECTIVISTA- } \\
\text { VIVENCIAL }\end{array}$ & $\begin{array}{l}\text { mundo social y cultural. } \\
\text { El conocimiento es un acto de } \\
\text { comprensión. }\end{array}$ & $\begin{array}{l}\text { Introspección } \\
\text { (con)vivencia }\end{array}$ & $\begin{array}{l}\text { Consenso } \\
\text { experiencial }\end{array}$ & $\begin{array}{l}\text { Verbal } \\
\text { académico }\end{array}$ & $\begin{array}{l}\text { Normas } \\
\text { creencias }\end{array}$ \\
\hline
\end{tabular}

Tabla 1: El enfoque epistemológico como orientador de la estructura global de la investigación

Deberíamos empezar por algún criterio de clasificación, aunque sea distinto al que se acaba de proponer, pero que sea un criterio fino, desagregador y potente, no uno de tipo simplista (como el de cualitativo/cuantitativo) o demasiado complejo (como parece serlo el de las inteligencias múltiples). No es que las tipologías de la tabla anterior sean las más relevantes ni las más adecuadas, pero sí resultan las mejor apoyadas con argumentos interteóricos (interdisciplinarios).

Ante esto, uno no puede más que asombrarse de clasificaciones tan confusas como las que ofrece, entre otros, el célebre Manual de la Upel, el cual ha sido copiado por la mayoría de nuestras universidades, en especial las privadas. Personalmente, tengo la convicción de que ese manual es uno de los más importantes factores de confusión en materia de formación de investigadores y de orientación para tesistas. Lo cito aquí porque es uno de los ejemplos más representativos de la mezcla de criterios clasificatorios mencionada arriba. Parte de considerar cuatro tipos o clases: la investigación de campo, la investigación documental, los proyectos factibles y los proyectos especiales. Aparte de la irrelevancia de esa clasificación, es notoria la mezcla de criterios (como en el caso relatado por Borges: los animales

primeras teorías cotidianas (es típica la pregunta "¿por qué?”). De ahí pasan a una fase de contrastación de conocimientos, cuando buscan averiguar si las teorías cotidianas son correctas (la fase en la que dejan de creer en la Cigüeña y el Niño Jesús, cuya pregunta típica es "¿cómo lo sé?", "¿quién lo dijo?”). Terminan su maduración cognitiva con la fase aplicativa, la de consolidación de destrezas y habilidades (“¿cómo lo hago?", "¿cómo lo resuelvo?”), la cual definitivamente parece anclar el predominio de un cierto estilo de pensamiento en el individuo. 
con pelo, los animales sin pelo y los animales del emperador). En efecto, la investigación de campo y la investigación documental obedecen al criterio de la fuente de los datos, mientras que los proyectos factibles y los proyectos especiales obedecen a la utilidad de las producciones investigativas. internacionalmente se sabe que los proyectos factibles son investigación aplicada o aplicativa (tecnologías materiales o humanas) y los especiales son elaboración técnica.

\subsection{Los objetivos de la investigación}

Este es otro de los puntos clave que encierra distintos obstáculos para una investigación social orientada al desarrollo masivo. Los obstáculos pueden ser vistos desde dos ánguIos: el problema del tipo de objetivos que definen la investigación científica en cuanto acción humana racional y el problema del diseño de un sistema de objetivos en los trabajos particulares de investigación.

\begin{tabular}{|c|c|c|c|c|}
\hline & DESCRIPTIVA & EXPLICATIVA & CONTRASTIVA & APLICATIVA \\
\hline EMPIRISTA & $\begin{array}{l}\text { Método de patrones de } \\
\text { frecuencia. } \\
\text { Procesamiento de la } \\
\text { información en datos } \\
\text { observables, agrupados } \\
\text { en variables. Uso de } \\
\text { estadística descriptiva } \\
\text { para el manejo y } \\
\text { presentación de los datos. }\end{array}$ & $\begin{array}{l}\text { Método inductivo. } \\
\text { Comprobación de hipótesis } \\
\text { observacionales mediante un } \\
\text { diseño experimental, basado en } \\
\text { estadística inferencial. }\end{array}$ & $\begin{array}{l}\text { Método experimental. } \\
\text { Réplicas de } \\
\text { comprobación } \\
\text { de hipótesis } \\
\text { mediante diseños } \\
\text { de base estadística } \\
\text { inferencial, variando } \\
\text { las condiciones de } \\
\text { prueba. }\end{array}$ & $\begin{array}{l}\text { Se derivan } \\
\text { tecnologías de acción } \\
\text { a partir de teorías } \\
\text { empiristas. } \\
\text { La tecnología } \\
\text { obtenida se valida } \\
\text { experimentalmente. }\end{array}$ \\
\hline RACIONALISTA & $\begin{array}{l}\text { Método de configuración } \\
\text { estructural. } \\
\text { Procesamiento de la } \\
\text { información en datos } \\
\text { observables, agrupados } \\
\text { en una estructura } \\
\text { empírica. Uso de lógica } \\
\text { de clases y cálculo de } \\
\text { relaciones para el manejo } \\
\text { y presentación de los } \\
\text { datos. }\end{array}$ & $\begin{array}{l}\text { Método deductivo. } \\
\text { Formulación de Hipótesis no } \\
\text { observacionales que expliquen } \\
\text { los hechos y a partir de las } \\
\text { cuales se deriven explicaciones } \\
\text { progresivamente más } \\
\text { específicas, que puedan ser } \\
\text { contrastadas. }\end{array}$ & $\begin{array}{l}\text { Método lógico- } \\
\text { formal y método } \\
\text { experimental. } \\
\text { Primero se prueba la } \\
\text { validez lógica de los } \\
\text { resultados de trabajo } \\
\text { y luego se realizan } \\
\text { pruebas empíricas. }\end{array}$ & $\begin{array}{l}\text { Se derivan } \\
\text { tecnologías de acción } \\
\text { a partir de teorías } \\
\text { racionalistas. } \\
\text { La tecnología } \\
\text { obtenida se } \\
\text { valida mediante } \\
\text { pruebas lógicas y } \\
\text { experimentales. }\end{array}$ \\
\hline INTROSPECTIVISTA & $\begin{array}{l}\text { Método de convivencia. } \\
\text { Procesamiento de } \\
\text { la información en } \\
\text { categorías de análisis, } \\
\text { agrupadas en constructos } \\
\text { hermenéuticos. Uso del } \\
\text { lenguaje verbal para el } \\
\text { manejo y presentación de } \\
\text { la información. }\end{array}$ & $\begin{array}{l}\text { Método vivencial-introspectivo } \\
\text { (aplicaciones hermenéuticas y/o } \\
\text { etnográficas). } \\
\text { Las categorías de análisis de } \\
\text { la fase anterior se resuelven en } \\
\text { una interpretación que permita } \\
\text { comprender los hechos implícitos } \\
\text { en el problema de investigación. }\end{array}$ & $\begin{array}{l}\text { Método consensual. } \\
\text { Los participantes } \\
\text { de la investigación } \\
\text { evalúan los resultados } \\
\text { de la investigación. }\end{array}$ & $\begin{array}{l}\text { Se derivan } \\
\text { propuestas de } \\
\text { intervención a } \\
\text { partir de teorías } \\
\text { introspectivistas. } \\
\\
\text { La propuesta } \\
\text { obtenida se valida } \\
\text { consensualmente. }\end{array}$ \\
\hline
\end{tabular}

Tabla 2: Tipos de Investigación según dos grandes criterios. 
En primer término, una de las mayores dificultades para una investigación orientada al desarrollo colectivo amplio está en lo que se concibe como el logro típico asociado a la acción de investigar. Por supuesto, eso conduce necesariamente a lo que se concibe como estructura lógica de dicha acción en general. Hay cierta tendencia a concebir el objetivo típico de la acción de investigar como el de crear un documento valioso, un discurso elegante, una pieza retórica o una obra emocionalmente impactante. Esta tendencia ha sido generada desde esas visiones posmodernistas, iluministas y esotéricas que, igual que en otras épocas históricas (más detalles en Padrón, 1996), han tomado auge después de la célebre "muerte del positivismo lógico". ${ }^{8}$ Para estas visiones investigar es una acción incluida en la de "charlar", "escribir bonito" o en la que busca, en suma, impactar a los lectores ignorantes o poco críticos. Desde esas visiones se quisiera que investigar fuera lo mismo que impresionar, algo parecido a lo que hacen los artistas, con la diferencia de que éstos suelen producir obras valiosas, apreciables por su técnica y/o por su creatividad, mientras que lo que se hace en estas visiones carece de cualquier técnica, de toda originalidad y, sobre todo, de cualquier sentido. Es, como decía Popper (1996: 88):

\section{[...] lanzar palabras al aire profesando una sabiduría que} no se posee. La receta consiste en tautologías y trivialidades condimentadas con paradójicos disparates. Otra receta es: escriba alguna pomposidad escasamente comprensible y añada trivialidades de vez en cuando. Esto lo disfrutará el lector, quien se sentirá lisonjeado por encontrar en un libro tan 'profundo' pensamientos que él ya tuvo alguna vez (cualquiera puede ver en estos días que las nuevas ropas del emperador están de moda) [...] No han aprendido lo difícil que es resolver problemas y acercarse a la verdad. Sólo han aprendido a ahogar a los demás seres humanos en un mar de palabras.

En segundo término, está el problema de cómo se concibe el diseño del sistema de objetivos en una investigación. Muchos de nuestros profesores de Metodología aun no entienden que un objetivo supone una acción y un logro asociado a esa acción, que un objetivo supone un desagregado de acciones y de logros menores, que los objetivos de una acción constituyen un sistema y que el diseño de un sistema de objetivos implica una visión planificadora, antes que una visión investigativa. Muchos desconocen, por ejemplo, que la suma semántica de los objetivos específicos debe ser igual al objetivo general. Muchos desconocen también que la formulación de un objetivo general obedece a la intención global del investigador y refleja el producto final de su acción. Desconocen que lo importante es la semántica de los logros de acción antes que la sintaxis, por lo cual suelen creer que todo objetivo va ne-cesariamente encabezado por un verbo y no también por un sustantivo (el producto de la acción). Algunos, incluso, tienen en mente una 'lista de los verbos' permitidos y de los prohibidos en la redacción de los objetivos. Algunos, por ejemplo, han llegado a decir que la palabra "explicar" no es un objetivo de investigación, cuando precisamente la gran meta de la Ciencia es la "explicación". Y, en general, muchos de nuestros profesores de Metodología ignoran que existe una teoría de la acción y una lógica de Objetivos, que son la referencia más sistemática con la que contamos para decidir si un sistema de objetivos está o no bien formulado. Y lo peor del caso es que es justamente esa sección de los "Objetivos de investigación" en la cual se centra la mayor parte de los ataques de nuestros evaluadores y es ahí donde abundan los comentarios del

\footnotetext{
8 Popper (1977) tiene un capítulo titulado "Quién mató al Positivismo Lógico" (p. 117) en el que se atribuye la autoría parcial de ese 'asesinato' epistemológico. Al comienzo del capítulo cita a John Passmore: "El Positivismo Lógico, pues, está muerto, o tan muerto como jamás lo ha estado un movimiento filosófico". Más adelante comenta: "Los filósofos de Inglate-rra y América parecen haberme tomado por un positivista lógico o, a lo más, por un positivista lógico disidente, que reemplazaba la verificabilidad por la falsabilidad (...). Pero para entonces el positivismo lógico había realmente muerto desde hacía algunos años."
} 
tipo "ese objetivo no sirve", "ese objetivo está mal formulado", etc., sin que propongan opciones de corrección y sin que sepan absolutamente nada de teoría de la acción ni de lógica de Objetivos.

El diseño del sistema de objetivos de una investigación es uno de los aspectos más sistemáticos y más sistemáticamente evaluables, pero en general nuestros evaluadores lo juzgan según sus opiniones personales, según sus criterios individuales y aun según sus gustos particulares. El tesista es la gran víctima de todo esto: de hecho, estoy convencido de que, si un tesista somete a consideración sus objetivos de trabajo ante cien evaluadores, obtendrá cien respuestas distintas.

En este renglón quedan muchos otros obstáculos particulares por describir, pero los que se acaban de mencionar dan una idea de esta clase de frenos epistemológicos. Por ejemplo, habría que analizar irracionalidades como esa de que las referencias bibliográficas no pueden tener más de cinco años. Por increíble que parezca, muchos evaluadores rechazan trabajos en cuya bibliografía aparezcan documentos de más de cinco o diez años de publicación. Es decir, según ellos, los trabajos de Einstein no sirven, porque cita a Newton, trescientos años antes. Tampoco sirven los trabajos de Chomsky, porque cita a Descartes, trescientos años antes. Y, en general, los mejores científicos de la historia habrían sido aplazados por estos profesores de Metodología, por considerar que todo conocimiento tiene un límite fijo y preciso de obsolescencia: cinco años. O sea, no hay conocimiento que valga para nada si pasa de cinco años de haber sido publicado.

También podrían analizarse cosas menores como, por ejemplo, que las investigaciones deben obedecer a una cierta cantidad de páginas o que los proyectos deben dividirse en "capítulos", olvidando que la división en capítulos es sólo para los libros. En fin, por más insignificantes que parezcan estos detalles, el hecho es que logran hacerle la vida imposible a cualquier tesista y que suelen ser maliciosamente utilizados. Y, como joya de la corona, resultan ser nuestros pobres estudiantes los que sufren del "Síndrome TMT" y los que necesitan una terapia adecuada. En verdad, al contrario de eso, lo que necesitamos es gigantescos hospitales para nuestros expertos en metodología y para nuestras insignes autoridades universitarias.

\section{LOS OBSTÁCULOS AXIOLÓGICOS}

Finalmente la tercera esfera desde donde se generan numerosos obstáculos para una investigación social orientada al desarrollo masivo (los más importantes e influyentes) es la de los valores, la de los sistemas preferenciales que están internalizados en las mentes individuales y grupales tanto de académicos como de administradores de instituciones académicas. Estos valores o sistemas preferenciales son tan poderosos que crean actitudes y disposiciones de acción que resultan estables y que, al final de todo, son los que generan los obstáculos organizacionales arriba reseñados.

No voy a describir casos ni ejemplos, sino sólo a puntualizar que aquí influye la concepción o el ideal que se tenga de una sociedad. $Y$ al respecto voy a distinguir, como dije al principio y como ya lo he hecho en varios trabajos, entre una concepción individualista de la sociedad y una concepción colectivista. No manejo el mismo sentido de Popper para esos dos términos: en este caso, el individualismo supone una visión piramidal de la sociedad, un espacio en el que las personas luchan por ubicarse en el vértice, donde cada vez caben menos personas, pero donde hay más privilegios, sobre la base del mecanismo de la competitividad, aquel mecanismo según el cual el propio progreso depende no sólo de conquistar espacios ascendentes sino también de que los demás competidores se estanquen o desciendan. 
Es decir, la competitividad supone el valor de la trampa, del engaño, de las apariencias y de las argucias, más que de Ios verdaderos méritos. El Colectivismo, en el lado opuesto, supone una visión rectangular de la sociedad, un espacio en el que todos tienen las mismas oportunidades y en el que no hay que competir, sino que el propio progreso depende del progreso de los demás.

El mecanismo que interviene en esto es la cooperación, la colaboración, el esfuerzo compartido por llegar todos a una meta. Un ejemplo adecuado que ya he citado antes para ilustrar esta diferencia es el caso histórico, reciente, documentado, de aquella carrera de niños con síndrome de Down, en el que uno de ellos se cae y todos los demás, en lugar de aprovechar esa caída para adelantar, se detienen, lo ayudan a levantarse y, todos agarrados de la mano, llegan juntos a la meta de la carrera, ante el estupor de todo un público competitivista. Esa gran lección de niños discapacitados, totalmente imprevista y espontánea, se convierte en una evidencia de que el colectivismo es menos utópico de lo que se ha dicho comúnmente. La diferencia entre ambas visiones puede explicarse mediante la frase: "hay dos clases de personas: las que luchan por reducir la brecha entre pobres y ricos y las que luchan por pertenecer a la clase de los ricos".

Esto tiene una perfecta aplicación a la investigación social: el Individualismo conduce a competitividades como las del PPI (Programa de Promoción del Investigador), el Conaba (Comisión Nacional de Beneficio Académico a los Profesores Universitarios) y demás estímulos oficiales, todos los cuales no hacen sino generar actitudes miserables en nuestros investigadores, actitudes dependientes de la necesidad mezquina de un poco más de dinero, correlativamente asociada a las necesidades ficticias de las sociedades de consu- mo (bellos carros, hermosas casas, hijos en colegios privados, etc.). Aparte de eso está el hecho obvio, comúnmente pasado por alto, de que en esos premios "ni son todos los que están ni están todos los que son". De ese modo, ante un análisis agudo y crítico, no resulta en sí mismo ningún mérito el pertenecer al nivel máximo del sistema PPI, sino, más bien, la sospecha de cuánta argucia burocrática podría subyacer a esa posición.

No hablemos de los tutores que cobran, de los asesores contratados, de las organizaciones privadas (integradas por académicos anónimos) que elaboran tesis, trabajos de ascenso e investigaciones por encargo bajo formas de pago ni hablemos de los mercenarios de la academia: los hay de muchos tipos, desde algunos de las universidades privadas hasta otros de los programas de doctorado y post-doctorado, pasando por nuestros profesores de "dedicación exclusiva" que tienen el don de la ubicuidad. En todo esto se imponen las hormas de esta visión individualista, en que la investigación social, básica y primitivamente, sirve para ascender, ganar puntajes y obtener más ingresos, en perfecta correspondencia con expectativas fatuas, vanidosas ( $y$, por tanto, falsas) de una noción de calidad de vida bajo esquemas consumistas.

He aquí el mayor obstáculo para una investigación social orientada al desarrollo de todos. De este obstáculo se derivan todos los anteriormente reseñados. Incluso, todos esos obstáculos antes mencionados resultan minúsculos ante la magnitud de estos otros. En consecuencia, sólo si afrontamos este obstáculo axiológico, de valores, sólo así podremos ir progresivamente luchando contra los demás obstáculos y sólo así tendremos una verdadera investigación social orientada a un verdadero 'desarrollo'. 


\section{REFERENCIAS}

- Araujo-Valero, C. (2009): Los Procesos de Socialización e Institucionalización del Arte. Tesis Doctoral en curso. Maracaibo: LUZ.

- Camacho, H. y Fontaines, T. (2004): “Análisis de tópicos en textos de metodología de la investigación", en ED, mayo, Vol.11, no.2, p.229-240. Disponible: http://www.serbi.luz. edu.ve/scielo.php?script=sci_arttext\&pid=S1315-407920 04005000006\&lng=es\&nrm=iso

- Einstein, A. (1989): "The Swiss Years: Writings, 1900-1909", en The Collected Papers of Albert Einstein. Volume 2. New Jersey, Princeton: Princeton University Press.

- García-Lobo, L. (2008): Conocimiento popular y académico como fundamento para la transformación productiva agroalimentaria. Tesis Doctoral en curso. Maracaibo: LUZ.

- Halliday, J. (1999): "Popper y la Filosofía de la Educación", en Encyclopedia of Philosophy of Education. Glasgow, UK: University of Strathclyde. Disponible: http://padron.entretemas.com/OtrasSecc/Descargas/PopperEducacion.htm

- Kuhn, T. S. (1962): The Structure of Scientific Revolutions, 1st. ed., Chicago: Univ. of Chicago Press.

- Olivares de Quintero, I. (2001): Un Modelo de Integración de las Funciones Universitarias Básicas: Docencia, Investigación y Extensión. Tesis Doctoral. Maracaibo: URBE/LINEA-i.

- Padrón, J.; Hernández, A.; Di Gravia, A. (2005): Epistemología. Tutorial Paso a Paso. Caracas: LINEA-i.

- Padrón, J. (1996): "La Neosofística y los Nuevos Sofismas", en Cinta de Moebio, Revista de Epistemología de Ciencias Sociales, $\mathrm{N}^{\circ}$. 8, Facultad de Ciencias Sociales, Universidad de Chile, Disponible: http://rehue.csociales.uchile.cl/publicaciones/moebio/08/padron.htm.

- Padrón, J. (1999): Referencias para una Revisión del Postgrado de la UNESR. Documento interno. Caracas: UNESR. Disponible: http://padron.entretemas.com/rev_doctorado_usr.htm

(2001): El Problema de Organizar la Investiga-

ción Universitaria, en Universidad Peruana Cayetano Heredia, Diálogos Universitarios de Postgrado. Volumen 11: Investigación en Postgrado; Elementos para el Análisis y
Propuestas.Noviembre-Diciembre, 2002, pp- 9-33. Disponible: http://padron.entretemas.com/Organizar_IU.htm (2004a): Relaciones entre la Universidad y sus Líneas de Investigación, en http://padron.entretemas. com/RelacUniv-Lineas.htm

(2004b): “Los Siete Pecados Capitales de la Investigación Universitaria Tercermundista", en Informe de Investigaciones Educativas, Vol. XVIII. Año 2004, pp. 69-80. Disponible: http://padron.entretemas.com/ 7PecCapInvUniv/index.htm

- _ (2005): “Los Doctorados en Ciencias Sociales ablandamiento académico y endurecimiento burocrátiCo", en INFORME DE INVESTIGACIONES EDUCATIVAS Vol: 19 Nro: 0 PP-0084.11/ E012-N2 2005. Disponible: http:// padron.entretemas.com/Ablandamiento.htm (2006): “Acerca de la Investigación Eucativa del Nivel Doctoral (Testimonios de un Tutor)", en Sánchez, J. (Comp.): Investigación Educativa. Un compromiso para Investigar y Aprender con Otros. Barquisimeto: CNU/OPSU/ UNESR. Pp. 71-94. Disponible: http://padron.entretemas. com/TestimonioDeUnTutor/Index.htm

(2007): "Acerca de las investigaciones llamadas "exploratorias"", en TERE. REVISTA DE FILOSOFÍA Y SOCIO POLITICA DE LA EDUCACIÓN Vol: 4 Nro: 7 PP-0230.6/E013N4 2007. Disponible: http://padron.entretemas.com/InvestExploratorias.htm

- ___ (2008): “Estilos de Pensamiento y Exclusión Social", en Entreciencias, Revista Científica Multidisciplinaria del CDCHT-UNESR. Julio, 2008, Vol. 1 No 1. Pp. 117-148. Disponible: http://padron.entretemas.com/EPyES.pdf

- Popper. K. (1992): In Search of a Better World. Lectures and Essays from Thirty years. Lon-don/NY: Routledge.

- _ _ (1977): Búsqueda sin Término. Madrid: Tecnos.

Rivero, N. (2000): Enfoques Epistemológicos y Estilos de Pensamiento. Tesis Doctoral. Caracas: UNESR/LINEA-i.

- Salinas, P. J. (1998): “El Síndrome TMT y el Síndrome TMA. Síntomas, efectos, Epidemiología, Etiología, Terapia y Contraindicaciones", en MedULA, Revista de Facultad de Medicina, Universidad de Los Andes. Vol. 7 No 1-4. Mérida. Venezuela. Editorial. Pp. 1-3.

- Valarino, E. (1991). El síndrome TMT. Todo, menos Tesis. Postgrado, 1, (1), 63-78 